\title{
ANALISIS KELAYAKAN FINANSIAL INDUSTRI PENYULINGAN MINYAK PALA (STUDI KASUS DI UD. PALATAMA RAYA KECAMATAN TAPAKTUAN KABUPATEN ACEH SELATAN)
}

\author{
Financial Feasibility Analysis of Nutmeg Oil Industry (Case Study at UD \\ Palatama Raya Kecamatan Tapaktuan, South Aceh Regency) \\ Hesti Rahmasari, Zakiah ${ }^{\mathbf{1}}$, Rahmaddiansyah ${ }^{\mathbf{1}^{*}}$ \\ ${ }^{1}$ Program Studi Agribisnis, Fakultas Pertanian, Universitas Syiah Kuala
}

\begin{abstract}
Abstrak. Penelitian ini bertujuan untuk mengetahui upaya UD. Palatama Raya dalam memenuhi bahan baku produksi minyak pala, menganalisis kelayakan finansial dan mengetahui sensitivitas pada UD. Palatama Raya. Penentuan lokasi penelitian dilakukan secara sengaja, dengan pertimbangan bahwa UD. Palatama Raya industiri penyulingan minyak pala yang paling lama bertahan di Tapaktuan. Penelitian ini menggunakan rumus kriteria kelayakan investasi NPV, Net B/C, IRR, PP, BEP, ROI dan analisis Sensitivitas. Hasil penelitian ini menunjukkan bahwa upaya UD. Palatama Raya untuk memenuhi bahan baku dalam memproduksi minyak pala yaitu menanam pala dilahan pribadi dan membeli pasokan bahan baku dari daerah luar Aceh Selatan. Berdasarkan kriteria kelayakan investasi pada UD. Palatama Raya dinyatakan layak dengan nilai NPV yaitu Rp. 601.522.887, Net B/C yaitu 1,50, IRR yaitu 47,55 \% dan PP 1,8 tahun. Berdasarkan hasil analisis BEP, dapat diketahui bahwa UD. Palatama Raya akan mengalami titik impas pada saat volume produksi yaitu 2.830 Kg dan mendapatkan omset sebesar Rp. 1.808.832.597 dalam setahun agar mencapai BEP. Berdasarkan hasil analisis ROI UD. Palatama Raya, kemampuan mengembalikan investasi produksi minyak pala pada tahun ke-1 yaitu sebesar $53,8 \%$, pada tahun ke-2 yaitu sebesar 56,5\% dan pada tahun ke-3 yaitu sebesar 60,1\%. UD. Palatama Raya paling sensitif terhadap penurunan harga jual dan penurunan volume produksi terjadi secara bersamaan.
\end{abstract}

Kata kunci: Kelayakan Finansial, Industri, Minyak Pala

\begin{abstract}
This study aims to determine the efforts of UD. Palatama Raya in the completion of fuel oil nutmeg production, analyze the financial feasibility and know the sensitivity of UD. Palatama Raya. Determining the location of the research is done intentionally, with the consideration that UD. Palatama Raya industiri is the longest surviving nutmeg oil in Tapaktuan. This study uses the formula of investment feasibility criteria of NPV, Net B / C, IRR, PP, BEP, ROI and Sensitivity analysis. The results of this study indicate that the efforts of UD. Palatama Raya to meet the raw materials in the manufacture of nutmeg oil is planting nutmeg in private land and buy raw materials from outside of South Aceh. Based on the investment feasibility criteria in UD. Palatama Raya declared feasible with the value of NPV is Rp. 601,522,887, Net B / C is 1.50, IRR is 47,55\% and PP 1,8 year. Based on the results of BEP analysis, it can be seen that UD. Palatama Raya will break even when the volume of production is $2,830 \mathrm{Kg}$ and get a turnover of $\mathrm{Rp} .1,808,832,597$ in a year to achieve the BEP. Based on ROI ROI analysis result. Palatama Raya, the ability to return the investment of nutmeg oil production in the first year is $53,8 \%$, in the second year that is equal to $56,5 \%$ and in the third year that is equal to $60,1 \%$. UD. Palatama Raya is most sensitive to the decline in selling prices and the decline in production volume occurs simultaneously.
\end{abstract}

Key Words: Financial Feasibility, Industry, Nutmeg Oil 


\section{PENDAHULUAN}

Indonesia menjadi salah satu penghasil pala yang terkemuka di dunia. Tanaman pala (Myristica fragrans houtt) adalah salah satu komoditas asli Indonesia yang dapat diolah menjadi bahan makanan, obat-obatan, parfum, kosmetik, dan lain-lain. Tanaman pala dapat dimanfaatkan bijinya dengan diolah menjadi minyak pala yang menghasilkan minyak atsiri dengan harga jual yang sangat tinggi mencapai jutaan rupiah. Minyak pala merupakan salah satu minyak atsiri dengan permintaan yang cukup tinggi di pasar internasional. Semakin berkembangnya industri pengolahan minuman, makanan, parfum, obat-obatan, aroma terapi, kosmetika dan lain-lain, maka semakin besar pula kebutuhan akan minyak atsiri tersebut. Untuk itu, pala sebagai sumber minyak atsiri berpeluang sangat baik untuk dikembangkan. Di Provinsi Aceh, Kabupaten Aceh Selatan yang di kenal dengan daerah Pala, merupakan daerah penghasil Pala terbesar kedua di Indonesia setelah provinsi Maluku, dan merupakan daerah sentra utama penghasil pala di provinsi Aceh.

Namun ada beberapa faktor yang perlu diperhatikan dalam upaya pengembangan produksi minyak atsiri seperti produk yang dihasilkan terjamin mutunya, harganya kompetitif dan adanya kontinuitas produksi. Harga pala saat ini sangat mengganggu perekonomian masyarakat Tapaktuan, penurunan harga biji pala berimbas pada menurunnya harga minyak pala, harga minyak pala dari semula mencapai hampir Rp 1 juta/kg turun menjadi Rp. 450.000/kg. Selain itu juga ada beberapa hal yang menjadi kendala dan mempengaruhi perkembangan industri penyulingan minyak pala UD. Palatama Raya yaitu keterbatasan bahan baku, hal ini disebabkan oleh tanaman pala di Aceh Selatan kini terserang hama yang mengakibatkan terbatasnya buah pala, secara otomatis berimbas kepada kapasitas jumlah produksi minyak pala yang terbatas juga dan menghasilkan keuntungan yang kurang maksimal dalam industri penyulingan minyak pala tersebut. Teknologi penyulingan minyak pala UD. Palatama Raya pada dasarnya sudah tersedia, namun beberapa teknologi yang diadopsi oleh industri tersebut masih menggunakan alat manual yang sudah lama, mengingat alat penyulingan modern yang mahal dan memerlukan investasi yang cukup tinggi, hal ini juga dapat mempengaruhi jumlah hasil produksi.

Tujuan dari penelitian ini adalah 1) Untuk mengetahui upaya industri penyulingan minyak pala UD. Palatama Raya untuk memenuhi bahan baku dalam memproduksi minyak pala. 2) Untuk menganalisis kelayakan finansial industri penyulingan minyak pala pada UD. Palatama Raya. 3) Untuk mengetahui kepekaan (sensitivity) usaha penyulingan minyak pala pada UD. Palatama Raya terhadap penurunan harga jual, penurunan volume produksi dan kenaikan harga bahan baku.

\section{METODE PENELITIAN}

Penelitian ini dilakukan di Desa Sawang Kajai Kecamatan Tapaktuan Kabupaten Aceh Selatan. Penentuan lokasi penelitian dilakukan secara purposive (sengaja), dengan pertimbangan bahwa UD. Palatama Raya bergerak pada komoditi pala khususnya penyulingan minyak pala dan memiliki prospek yang menjanjikan serta UD. Palatama Raya merupakan industri penyulingan minyak pala yang paling lama bertahan di Tapaktuan. Penelitian ini dilaksanakan pada bulan oktober 2017.

Analisis Kelayakan Finansial Industri Penyulingan Minyak Pala Studi Kasus di UD.Palatama 243 Raya Kecamatan Tapaktuan Kabupaten Aceh Selatan (Hesti Rahmasari, Rahmaddiansyah, Zakiah) Jurnal Ilmiah Mahasiswa Pertanian Unsyiah, Vol 3, No 2, Mei 2018: 242-255 
Objek dari penelitian ini adalah industri penyulingan minyak pala di Desa Sawang Kajai Kecamatan Tapaktuan Kabupaten Aceh Selatan. Sedangkan ruang lingkup dari penelitian ini terbatas pada analisis kelayakan finansial industri penyulingan minyak pala dan analisis sensitivitas industri penyulingan minyak pala terhadap perubahan seperti penurunan harga jual, penurunan volume produksi dan kenaikan harga bahan baku.

Metode yang digunakan dalam penelitian ini adalah analisis kualitatif dan kuantitatif. Analisis kualitatif (deskriptif) yaitu mendefenisikan gambaran umum perusahaan. Sedangkan analisis kuantitatif (statistik) yaitu menganalisis kelayakan finansial berdasarkan kriteria yang digunakan dalam studi kelayakan pada UD. Palatama Raya. Metode analisis yang digunakan dalam penelitian ini analisis kriteria kelayakan investasi, analisis BEP, analisis ROI dan analisis sensitivitas. Untuk mengetahui besarnya keuntungan, total penerimaan dan total biaya yang diperoleh industri penyulingan minyak pala dapat dihitung dengan rumus sebagai berikut:

a. Keuntungan

$$
\pi=\mathrm{TR}-\mathrm{TC}
$$
(Soeheroe, 1994)

Keterangan:

$\pi \quad=$ Keuntungan (Rp/Bulan)

TR = Jumlah nilai yang didapat dari penjualan minyak (Rp/Bulan)

$\mathrm{TC}=$ Jumlah biaya yang dikeluarkan dikeluarkan (Rp/Bulan)

b. Total Revenue (Total Penerimaan) dapat dihitung mengunakan rumus:

$$
\mathrm{TR}=\mathrm{P} \times \mathrm{Q}
$$
(Soeheroe, 1994)

Keterangan:

TR = Jumlah nilai yang didapat dari penjualan minyak pala (Rp/Bulan)

$\mathrm{P} \quad=$ Harga minyak pala $(\mathrm{Rp} / \mathrm{Kg})$

$\mathrm{Q} \quad=$ Jumlah minyak pala bersih $(\mathrm{Kg})$

c. Total Cost (Total Biaya) dapat dihitung dengan rumus:

$$
\mathrm{TC}=\mathrm{FC}+\mathrm{VC}
$$
(Soeheroe, 1994)

Keterangan:

$\mathrm{TC}=$ Biaya yang dikeluarkan (Rp/Bulan)

$\mathrm{FC} \quad=$ Biaya tetap $(\mathrm{Rp} /$ Bulan $)$

$\mathrm{VC}=$ Biaya variabel $(\mathrm{Rp} / \mathrm{Kg})$

\section{Analisis Kelayakan Finansial}

Pendekatan analisis finansial berdasarkan metode kriteria yang digunakan dalam kajian ini yaitu:

\section{a. Net Present Value (NPV)}

Analisis Kelayakan Finansial Industri Penyulingan Minyak Pala Studi Kasus di UD.Palatama 244 Raya Kecamatan Tapaktuan Kabupaten Aceh Selatan (Hesti Rahmasari, Rahmaddiansyah, Zakiah) Jurnal Ilmiah Mahasiswa Pertanian Unsyiah, Vol 3, No 2, Mei 2018: 242-255 
Net Present Value (NPV) merupakan nilai sekarang dari selisih manfaat (benefit) dengan biaya (cost) pada tingkat suku bunga tertentu (Gittinger, 1986). Dapat dirumuskan sebagai berikut:

$$
\mathrm{NPV}=\sum_{\mathrm{t}=1}^{\mathrm{n}} \frac{\mathrm{Bt}-\mathrm{Ct}}{(1+i)^{t}}
$$

Keterangan :

$\mathrm{NPV}=$ Net Present Value $(\mathrm{Rp})$

$\mathrm{B} \quad=$ Benefit $(\mathrm{Rp} / \mathrm{Tahun})$

$\mathrm{C} \quad=$ Cost $(\mathrm{Rp} /$ Tahun $)$

$\mathrm{t} \quad=$ Waktu (Tahun)

$\mathrm{i} \quad=$ Tingkat suku bunga bank $(\%)$

Kriteria pengukuran pada analisis ini adalah:

1. Jika NPV $>0$, maka industri penyulingan minyak pala layak untuk diusahakan

2. Jika NPV < 0, maka industri penyulingan minyak pala tidak layak untuk diusahakan

3. Jika NPV $=0$, maka industri penyulingan minyak pala dalam keadaan Break Event Point

b. Net Benefit Cost Ratio (Net B/C Ratio)

Net benefit cost ratio (Net B/C Ratio) merupakan hasil bagi antara manfaat bersih yang bernilai positif dengan manfaat bersih yang bernilai negatif (Kadariah,1986). Dapat dirumuskan sebagai berikut:

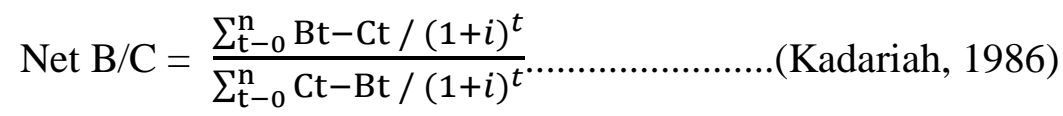

Keterangan:

$$
\begin{array}{ll}
\mathrm{Net} B / \mathrm{C} & =\text { Net Benefit Cost Ratio } \\
\mathrm{Bt} & =\text { Manfaat bersih tahun } \mathrm{t}(\mathrm{Rp}) \\
\mathrm{Ct} & =\text { Biaya pada tahun } \mathrm{t}(\mathrm{Rp}) \\
\mathrm{i} & =\text { Tingkat suku bunga yang berlaku (\%) } \\
\mathrm{t} & =\text { Waktu (Tahun) }
\end{array}
$$

Kriteria pengukuran pada analisis ini adalah:

1. Jika Net $\mathrm{B} / \mathrm{C}>1$, maka industri penyulingan minyak pala layak untuk diusahakan

2. Jika Net $\mathrm{B} / \mathrm{C}<1$, maka industri penyulingan minyak pala tidak layak untuk diusahakan

3. Jika Net $\mathrm{B} / \mathrm{C}=1$, maka industri penyulingan minyak pala dalam keadaan Break Event Poin.

c. Internal Rate of Return (IRR)

Internal Rate of Return (IRR) merupakan tingkat diskonto maksimum yang dapat membuat arus penerimaan bersih sekarang dari suatu bisnis atau NPV sama dengan nol (Gittinger, 1986). Dapat dirumuskan sebagai berikut:

Analisis Kelayakan Finansial Industri Penyulingan Minyak Pala Studi Kasus di UD.Palatama 245 Raya Kecamatan Tapaktuan Kabupaten Aceh Selatan (Hesti Rahmasari, Rahmaddiansyah, Zakiah) Jurnal Ilmiah Mahasiswa Pertanian Unsyiah, Vol 3, No 2, Mei 2018: 242-255 


$$
\mathrm{IRR}=\mathrm{i}_{1}+\frac{\mathrm{NPV}_{1}}{\left(\mathrm{NPV}_{1}-\mathrm{NPV}_{2}\right)} x\left(i_{2-} i_{1}\right) \ldots \ldots \ldots \ldots \ldots \ldots \ldots \ldots(\text { Gittinger, 1986) }
$$

Keterangan:

IRR = Tingkat pengembalian internal (\%)

$\mathrm{i}_{1} \quad=$ Tingkat discount rateyang menghasilkan $\mathrm{NPV}_{1}(\%)$

$\mathrm{i}_{2} \quad=$ Tingkat discount rateyang menghasilkan $\mathrm{NPV}_{2}(\%)$

Kriteria pengukuran pada analisis ini adalah:

1. Apabila IRR > dari bunga pinjaman, maka proyek diterima

2. Apabila IRR < dari bunga pinjaman, maka proyek ditolak

3. Apabila IRR = bunga pinjaman, maka proyek dalam keadaanimpas (Break Event Point)

d. Payback Period (PP)

Payback period (PP) merupakan kriteria tambahan dalam analisis kelayakan untuk melihat periode waktu yang diperlukan untuk melunasi seluruh pengeluaran investasi dari perusahaan (Rangkuti, 2004). Dapat dirumuskan sebagai berikut:

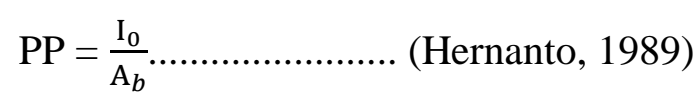

Keterangan:

$\mathrm{Pp} \quad=$ Payback Period (Bulan)

$\mathrm{I}_{0} \quad=$ Investasi awal (Rp)

$\mathrm{A}_{\mathrm{b}} \quad=$ Manfaat (benefit) yang diperoleh setiap periode (Rp/Bulan)

Kriteria pengambilan keputusan:

1. Jika masa pengembalian (Payback Period) < umur ekonomis proyek, maka proyek dapat dilanjutkan.

2. Jika masa pengembalian (Payback Period) $>$ umur ekonomis proyek, maka proyek tidak layak untuk dilaksanakan.

e. Break Event Point (BEP)

Analisis Break Event Point (BEP) bertujuan sampai batas mana usaha yang dilakukan dapat memberikan keuntungan atau pada tingkat tidak rugi dan tidak untung. Estimasi ini digunakan dalam kaitannya antara pendapatan dan biaya (Syarif, 2011). Rumusnya sebagai berikut:

$$
\begin{gathered}
\text { BEP Harga }=\frac{\mathrm{FC}}{1-(\mathrm{VC} / \mathrm{S})} \ldots \ldots \ldots \ldots \ldots . . . . . .(\text { Syarif, } 2011) \\
\text { BEP Unit } \left.=\frac{\mathrm{FC}}{\mathrm{P}-\mathrm{VC}} \ldots \ldots \ldots \ldots \ldots . . . . . . . \text { Syarif, } 2011\right)
\end{gathered}
$$

Keterangan:

BEP harga : Break Even Point pada omset penjualan (Rp)

BEP Unit : Break Even Point pada volume produksi (Kg)

FC : Total Biaya Tetap $(\mathrm{Rp} / \mathrm{Kg})$

VC : Biaya Variabel (Rp/Bulan)

Analisis Kelayakan Finansial Industri Penyulingan Minyak Pala Studi Kasus di UD.Palatama 246 Raya Kecamatan Tapaktuan Kabupaten Aceh Selatan (Hesti Rahmasari, Rahmaddiansyah, Zakiah) Jurnal Ilmiah Mahasiswa Pertanian Unsyiah, Vol 3, No 2, Mei 2018: 242-255 
P : Harga Jual per Unit $(\mathrm{Rp} / \mathrm{Kg})$

$\mathrm{S} \quad$ : Total Penjualan $(\mathrm{Rp} / \mathrm{Kg})$

f. Return on Investment (ROI)

Return on Investment (ROI) merupakan perbandingan antara keuntungan atau laba bersih dengan biaya yang dikeluarkan untuk memperoleh keuntungan tersebut (Sutrisno, 2001). Rumusnya sebagai berikut:

$$
\mathrm{ROI}=\frac{\mathrm{TR}}{\mathrm{TC}} \times 100 \% \text {.........(Kasmir dan Jakfar, 2004) }
$$

Keterangan:

ROI : Return on Investment (\%)

TR : Total Keuntungan Setelah Pajak (Rp/Bulan)

TC : Total Biaya Produksi (Rp/Bulan)

\section{Analisis Sensitivitas}

Analisis sensitivitas dilakukan untuk meneliti kembali suatu analisis kelayakan bisnis, agar dapat melihat berpengaruh yang akan terjadi terhadap keadaan yang selalu berubah atau ada suatu kesalahan dalam perhitungan manfaat dan biaya. Adapun perubahan-perubahan pada analisis sensitivitas adalah sebagai berikut:

a. Penurunan harga jual yang telah terjadi dan batas kelayakan usaha

b. Penurunan volume hasil produksi yang telah terjadi dan batas kelayakan produksi

c. Kenaikan biaya produksi yang telah terjadi dan batas kelayakan produksi

Setelah melakukan analisis sensitivitas, akan diketahui seberapa jauh dampak perubahan-perubahan tersebut terhadap kelayakan bisnis dan sampai tingkat mana proyek masih layak dilanjutkan. Lalu dilakukan perhitungan laju kepekaan (sensitivitas) untuk melihat keadaan dimana setelah terjadinya perubahan, berapa tingkat kepekaan (sensitivitas) terhadap perubahan tersebut yang terdiri dari penurunan harga jual, penurunan volume produksi dan kenaikan harga bahan baku pada kriteria kelayakan investasi. Adapun analisis laju kepekaan (sensitivitas) dapat dirumuskan sebagai berikut :

$$
\text { Laju Kepekaan }=\frac{\frac{X 1-X 0}{\bar{X}} \times 100 \%}{\frac{y 1-y 0}{\bar{Y}} \times 100 \%} \ldots \ldots \ldots \ldots \ldots \ldots \ldots \ldots . . . . . . . . .(D j a m i n, 1992)
$$

Keterangan :

$\mathrm{X} 1=$ Net BC Ratio/NPV/IRR/PP setelah terjadi perubahan

$\mathrm{XO}=$ Net BC Ratio/NPV/IRR/PP sebelum terjadi perubahan

$\mathrm{X}=$ Rata-rata perubahan

Y1 = Harga jual/ Biaya produksi/ Produksi setelah terjadi perubahan

Y0 = Harga jual/ Biaya produksi/ Produksi sebelum terjadi perubahan

$\mathrm{Y}=$ Rata-rata perubahan

Kriteria Perubahan :

Analisis Kelayakan Finansial Industri Penyulingan Minyak Pala Studi Kasus di UD.Palatama 247 Raya Kecamatan Tapaktuan Kabupaten Aceh Selatan (Hesti Rahmasari, Rahmaddiansyah, Zakiah) Jurnal Ilmiah Mahasiswa Pertanian Unsyiah, Vol 3, No 2, Mei 2018: 242-255 
1. Jika laju perubahan $>1$, maka hasil kegiatan industri penyulingan minyak pala peka/sensitiv terhadap perubahan.

2. Jika laju perubahan $<1$, maka hasil kegiatan industri penyulingan minyak pala tidak peka/sensitiv terhadap perubahan.

\section{Gambaran Umum Perusahaan}

\section{HASIL PENELITIAN DAN PEMBAHASAN}

\section{Sejarah Berdiri dan Lokasi Perusahaan}

UD. Palatama Raya merupakan industri kecil menengah (UKM) yang bergerak pada usaha pengolahan pala menjadi minyak pala. Industri ini merupakan salah satu usaha pembuatan minyak pala yang menggunakan mesin manual dan sudah bertahan sejak 16 tahun yang lalu. Industri ini didirikan pada tahun 2001 oleh Bapak H. Nasruddin yang bertempat tinggal di Desa Sawang Kajai Kecamatan Tapaktuan Kabupaten Aceh Selatan. Industri penyulingan minyak pala ini awalnya berdiri karena pemilik sangat gemar memakai minyak pala yang dibeli dari luar kota untuk mengobati rasa pegal ditubuh. Sehingga pemilik ingin membuka usaha produksi minyak pala pribadi, dengan didukung oleh bahan baku yang mudah didapat karena lokasi perusahaan pun berada di daerah sentra penghasil pala terbesar di Aceh.

\section{Sistem Manajemen Perusahaan}

Saat ini perusahaan memperkerjakan 2 orang tenaga kerja yang bekerja pada proses penyulingan minyak pala dari penggilingan, pengukusan, pendinginan serta pengemasan. Industri ini melakukan penyulingan minyak pala dalam sebulan ratarata 4 kali dengan waktu penyulingan selama 72 jam atau 3 hari 3 malam atau jumlah hari kerja yaitu 12 hari/bulan. Fasilitas yang diberikan kepada tenaga kerja yaitu berupa kamar untuk istirahat dan kamar mandi.

\section{Sarana Produksi}

Sarana yang digunakan dalam industri penyulingan minyak pala ini yaitu: sarana penyediaan air, sarana penyediaan listrik, Sarana komunikasi, Sarana sirkulasi air dan sarana transportasi.

\section{Teknis dan Produksi}

\section{Bahan baku}

Untuk memenuhi bahan baku dalam memproduksi minyak pala, awalnya perusahaan ini menanam pala dilahan pribadi. Tetapi masalah hama dan penyakit yang menyerang tanaman pala tidak dapat dihindarkan, sehingga perusahaan ini menutup lahan tanaman pala yang masih baru tersebut dan memenuhi bahan baku dengan cara membeli biji dan fuli pala dari daerah lainnya yang ada di Aceh seperti Aceh Barat Daya yang merupakan daerah penghasil pala setelah Aceh Selatan. Adapun rincian harga biji pala dapat dilihat pada Tabel 1.

Tabel 1. Rata-Rata Harga Biji Pala Tahun 2017.

\begin{tabular}{ccr}
\hline No. & Jenis Pala & Harga Biji Pala (Rp/Kg) \\
\hline 1. & Pala A & 85.000 \\
2. & Pala B & 45.000 \\
3. & Pala C & 65.000 \\
\hline & Rata-rata & $\mathbf{6 5 . 0 0 0}$ \\
\hline
\end{tabular}

Sumber: Data primer 2017 (diolah)

Analisis Kelayakan Finansial Industri Penyulingan Minyak Pala Studi Kasus di UD.Palatama 248 Raya Kecamatan Tapaktuan Kabupaten Aceh Selatan (Hesti Rahmasari, Rahmaddiansyah, Zakiah) Jurnal Ilmiah Mahasiswa Pertanian Unsyiah, Vol 3, No 2, Mei 2018: 242-255 
Berdasarkan Tabel 1 diatas, dapat dilihat bahwa rata-rata harga biji pala yaitu Rp. $65.000 / \mathrm{kg}$, harga biji pala yang paling rendah yaitu jenis pala B dengan harga Rp. 45.000/kg. Biji pala memiliki standar mutu SNI 01-0006-1993 dalam penyulingan minyak pala yaitu biji pala muda yang mengandung minyak pala lebih besar sebanyak 14-17 \% dengan umur panen 3-4 bulan (pala grade A) dan biji pala tua yang mengandung minyak pala lebih rendah sebanyak 8-12\% dengan umur panen 4-5 bulan (pala grade B).

Bahan baku yang dibutuhkan untuk memproduksi minyak pala tidak hanya biji pala kering saja, tapi juga dibutuhkan fuli pala kering untuk meningkatkan rendemen minyak pala. Harga fuli pala kering yaitu Rp. 180.000/kg. Setiap 1 kali proses produksi (penyulingan) komposisinya $80 \%$ biji pala kering grade A,B atau $\mathrm{C}$ dan $20 \%$ fuli pala kering, dimana harga rata-rata pala kering berdasarkan tabel 5 yaitu Rp. 65.000 dan penggunaan bahan baku dalam sekali proses produksi atau sekali penyulingan yaitu $1.500 \mathrm{~kg}$. Jadi, perusahaan mengeluarkan biaya bahan baku (biji pala kering dan fuli) yaitu Rp. 132.000.000/sekali produksi. Adapun rincian total biaya bahan baku dapat dilihat pada Tabel 2 .

Tabel 2. Total Biaya Bahan Baku dalam Setiap Proses Produksi (2017).

\begin{tabular}{|c|c|c|c|c|}
\hline No. & Bahan Baku & $\begin{array}{c}\text { Harga } \\
\text { (Rp/Kg) }\end{array}$ & $\begin{array}{c}\text { Jumlah Bahan } \\
\text { Baku (Kg) }\end{array}$ & $\begin{array}{c}\text { Jumlah Biaya } \\
\text { Bahan Baku } \\
(\text { Rp) } \\
\end{array}$ \\
\hline 1. & Biji Pala (A,B dan C) & 65.000 & 1200 & 78.000 .000 \\
\hline 2. & Fuli Pala & 180.000 & 300 & 54.000 .000 \\
\hline & Total & & & $\overline{132.000 .000}$ \\
\hline
\end{tabular}

Berdasarkan Tabel 2 diatas, dapat diketahui bahwa total jumlah biaya bahan baku yaitu Rp. 132.000.000 per sekali penyulingan/produksi dengan bahan baku sebanyak $1500 \mathrm{Kg}$. Dalam sebulan dilakukan 4 kali proses produksi, maka total biaya bahan baku yaitu Rp. 528.000.000/bulan.

\section{Tenaga kerja}

Saat ini UD. Palatama Raya mempekerjakan 2 orang untuk memproduksi minyak pala yang bekerja dalam proses penggilingan, penyulingan dan pengemasan. Penggajiannya dihitung dalam $1 \mathrm{~kg}$ minyak pala yang dihasilkan yaitu $2.500 / \mathrm{kg}$. Kedua tenaga kerja di UD. Palatama Raya adalah lulusan SMA yang tidak melanjutkan sekolah sehingga bekerja di perusahaan ini. Tenaga kerja tersebut juga diberikan fasilitas berupa kamar tidur untuk istirahat dan kamar mandi.

\section{Teknologi}

Teknologi yang digunakan dalam memproduksi minyak pala yaitu ketel suling, tungku pemanas dan boiler, pengering, bak pendingin, penampung minyak (Oil Separator), mesin penggiling (Roler), timbangan, Peralatan bantu lainnya yang terdiri dari kipas angin, kereta sorong dan sekop.

\section{Proses Produksi}

Proses produksi minyak pala pada UD. Palatama Raya terdiri dari beberapa tahap. Tahapan tersebut yaitu penyediaan bahan baku, penggilingan bahan baku, destilasi (penyulingan), pendinginan, pemisahan, pengemasan

Analisis Kelayakan Finansial Industri Penyulingan Minyak Pala Studi Kasus di UD.Palatama 249 Raya Kecamatan Tapaktuan Kabupaten Aceh Selatan (Hesti Rahmasari, Rahmaddiansyah, Zakiah) Jurnal Ilmiah Mahasiswa Pertanian Unsyiah, Vol 3, No 2, Mei 2018: 242-255 


\section{Pemasaran Produksi Minyak Pala \\ Produk}

Produk utama yang dihasilkan yaitu minyak pala. Diperoleh dari hasil penyulingan biji dan fuli pala. Minyak fuli baunya lebih tajam dari pada minyak biji pala, biasanya penyulingan dilakukan dengan mencampur biji dan fuli pala agar minyak yang dihasilkan lebih baik. Bahan baku biji dan fuli pala yang digunakan berasal dari biji pala muda dan biji pala tua. Adapun produk minyak pala yang dihasilkan dalam sekali penyulingan yaitu $200 \mathrm{~kg}$.

\section{Harga}

Harga minyak pala yang saat ini berlaku di tingkat pedagang besar di Medan dan Padang adalah berturut-turut yaitu sekitar Rp. $760.000 / \mathrm{kg}$. Untuk ekspor, minyak pala dipengaruhi oleh harga yang berlaku di pasaran internasional.

\section{Analisis Kelayakan Finansial}

Biaya

Biaya atau kebutuhan dan sumber dana yang digunakan untuk mendirikan UD. Palatama Raya yaitu $40 \%$ modal pribadi dan $60 \%$ modal pinjaman Bank. Biaya-biaya yang dikeluarkan yaitu biaya investasi dan biaya operasional. Untuk biaya investasi yaitu sebesar Rp. 1.200.230.000, biaya tersebut digunakan untuk pembelian alat dan mesin penyulingan minyak pala, bangunan pabrik, bangunan gudang, serta kendaraan. Sedangkan biaya operasional merupakan biaya yang dikeluarkan untuk kebutuhan biaya variabel dan biaya tetap. Biaya variabel yang dikeluarkan yaitu Rp. 6.428.688.000 per tahun, biaya tetap yang dikeluarkan yaitu Rp. 31.800.000 per tahun, dan total biaya operasional yaitu Rp. 6.460 .488 .000 per tahun.

\section{Manfaat}

Manfaat atau pendapatan kotor yaitu nilai dari penjualan hasil produksi minyak pala. Setiap sekali penyulingan biji dan fuli pala akan menghasilkan 200 $\mathrm{Kg}$ minyak pala, maka dalam satu bulan volume yang dihasilkan yaitu $800 \mathrm{Kg}$. Total arus manfaat yang diterima UD. Palatama Raya yaitu Rp. 7.296.000.000 per tahun

\section{Arus Kas (Cash Flow)}

Arus kas pada industri penyulingan minyak pala terdiri dari manfaat sebagai arus masuk (penerimaan) dan biaya sebagai arus keluar (pengeluaran). Arus kas (cashflow) yang diperhitungkan dalam analisis ini dimulai pada arus kas yang terjadi pada tahun ke-nol hingga tahun ketiga. Arus kas yang terjadi pada tahun ke0 merupakan arus kas yang terjadi pada saat minyak pala belum diproduksi dan merupakan biaya investasi awal usaha. Arus kas yang diperhitungkan pada tahun ke-1 merupakan data hasil penelitian yang dilakukan di UD. Palatama Raya di Kecamatan Tapaktuan Kabupaten Aceh Selatan.

\section{Analisis Kriteria Kelayakan Investasi}

Analisis kriteria kelayakan investasi yang digunakan untuk menilai industri penyulingan minyak pala adalah NPV (Net Present Value), Net B/C (Net Benefit

Analisis Kelayakan Finansial Industri Penyulingan Minyak Pala Studi Kasus di UD.Palatama 250 Raya Kecamatan Tapaktuan Kabupaten Aceh Selatan (Hesti Rahmasari, Rahmaddiansyah, Zakiah) Jurnal Ilmiah Mahasiswa Pertanian Unsyiah, Vol 3, No 2, Mei 2018: 242-255 
Cost Ratio), IRR (Internal Rate Of Return), PP (Payback Period). Adapun hasil perhitungan kriteria kelayakan investasi UD. Palatama Raya yaitu:

1. NPV (Net Present Value)

Industri penyulingan minyak pala ini menghasilkan NPV atau keuntungan bersih pada akhir proyek yaitu Rp. 601.522.887. Karena nilai NPV > 0, maka usaha ini layak dilaksanakan.

2. Net B/C (Net Benefit Cost Ratio)

Industri penyulingan minyak pala ini menghasilkan nilai Net B/C sebesar 1,50. Artinya industri penyulingan minyak pala ini layak untuk dilaksanakan karena nilai Net $\mathrm{B} / \mathrm{C}>1$.

3. IRR (Internal Rate Of Return)

Industri penyulingan minyak pala ini layak untuk diusahakan karena memperoleh IRR > $18 \%$ yaitu 47,55\%.

4. Payback Period

Payback Period hanya digunakan untuk menentukan waktu pengembalian investasi. Payback Period dari industri penyulingan minyak pala ini yaitu 1,8 tahun. Berdasarkan hasil analisis kriteria investasi yang meliputi NPV, Net B/C, IRR dan PP, maka secara ringkas dapat dilihat pada Tabel 3.

Tabel 3. Hasil Analisis Kriteria Kelayakan Investasi Pada Industri Penyulingan Minyak Pala UD. Palatama Raya (2017).

\begin{tabular}{clcc}
\hline No. & Kriteria Kelayakan Investasi & Hasil Analisis & Keterangan \\
\hline 1. & NPV (Net Present Value $)$ & Rp. 601.522 .887 & Layak \\
2. & Net B/C $($ Net Benefit Cost Ratio $)$ & 1,50 & Layak \\
3. & IRR (Internal Rate Of Return $)$ & $47,55 \%$ & Layak \\
4. & PP $($ Payback Period $)$ & 1,8 tahun & \\
\hline
\end{tabular}

Sumber: Data primer 2017 (diolah)

\section{Analisis BEP (Break Even Point)}

Perhitungan BEP pada industri penyulingan minyak pala ini ditinjau berdasarkan harga jual dan volume produksi. Adapun hasil perhitungan analisis BEP dapat dilihat pada Tabel 4.

Tabel 4. Hasil Analisis Break Even Point pada Industri Penyulingan Minyak Pala UD. Palatama Raya (2017).

\begin{tabular}{clr}
\hline No. & Uraian & \multicolumn{1}{c}{ Hasil } \\
\hline 1. & BEP Harga $(\mathrm{Rp})$ & 1.808 .832 .597 \\
2. & BEP Unit $(\mathrm{Kg})$ & 2.830 \\
\hline \multicolumn{2}{l}{ Sumber: Data primer 2017 (diolah) }
\end{tabular}

Berdasarkan Tabel 10 diatas, dapat diketahui bahwa UD. Palatama Raya akan mengalami titik impas pada saat volume produksi yaitu $2.830 \mathrm{Kg}$ dan mendapatkan omset sebesar Rp. 1.808.832.597 dalam setahun agar mencapai BEP. Analisis ROI (Return On Investment)

Analisis ROI dapat dilakukan setelah perhitungan rugi laba usaha yang meliputi total penerimaan, total pengeluaran, keuntungan sebelum pajak dan

Analisis Kelayakan Finansial Industri Penyulingan Minyak Pala Studi Kasus di UD.Palatama 251 Raya Kecamatan Tapaktuan Kabupaten Aceh Selatan (Hesti Rahmasari, Rahmaddiansyah, Zakiah) Jurnal Ilmiah Mahasiswa Pertanian Unsyiah, Vol 3, No 2, Mei 2018: 242-255 
keuntungan setelah pajak. Adapun hasil perhitungan analisis ROI dapat dilihat pada Tabel 5.

Tabel 5. Hasil Analisis Return On Investment pada Industri Penyulingan Minyak Pala UD. Palatama Raya (2017).

\begin{tabular}{cccccc}
\hline \multirow{2}{*}{ No. } & \multirow{2}{*}{ Uraian } & \multicolumn{4}{c}{ Tahun } \\
\cline { 3 - 6 } & & $\mathbf{0}$ & $\mathbf{1}$ & $\mathbf{2}$ & $\mathbf{3}$ \\
\hline 1. & Laba Setelah Pajak & $645.677 .862,6$ & $677.988 .862,7$ & $720.907 .619,9$ \\
2. & Total Biaya Investasi & 1.200 .230 .000 & 1.200 .230 .000 & 1.200 .230 .000 \\
3. & Return on Investment & 53,8 & 56,5 & 60,1 \\
\hline Sumber: Data primer 2017 (diolah) & & &
\end{tabular}

Berdasarkan Tabel 5 diatas, dapat diketahui bahwa kemampuan mengembalikan investasi produksi minyak pala pada tahun ke-1 yaitu sebesar 53,8 $\%$, pada tahun ke-2 yaitu sebesar 56,5 \% dan pada tahun ke-3 yaitu sebesar 60,1\%.

\section{Analisis Sensitivitas}

Untuk melakukan analisis sensitivitas, penulis mengasumsikan bahwa yang berpengaruh terhadap inflasi pada UD. Palatama Raya adalah penurunan harga jual dan penurunan volume produksi yang berpengaruh terhadap pendapatan, serta kenaikan harga bahan baku yang berpengaruh terhadap biaya operasional yaitu sebesar $5 \%$. Ditentukan berdasarkan rata-rata tingkat inflasi Indonesia tahun 20142016. Untuk lebih mudah melihat hasil perhitungan analisis sensitivitas tersebut, secara ringkas dapat dilihat pada Tabel 6.

Tabel 6. Ringkasan Hasil Analisis Sensitivitas pada UD. Palatama Raya (2017).

\begin{tabular}{|c|c|c|c|c|c|c|c|}
\hline \multirow[b]{2}{*}{ No. } & \multirow{2}{*}{$\begin{array}{c}\text { Harga } \\
\text { Jual } \\
\text { (turun) }\end{array}$} & \multirow{2}{*}{$\begin{array}{c}\text { Volume } \\
\text { Produksi } \\
\text { (turun) }\end{array}$} & \multirow{2}{*}{$\begin{array}{c}\text { Harga } \\
\text { Bahan } \\
\text { Baku } \\
\text { (naik) }\end{array}$} & \multicolumn{4}{|c|}{ Kriteria Kelayakan Investasi } \\
\hline & & & & NPV (Rp) & $\begin{array}{l}\text { Net } \\
\text { B/C }\end{array}$ & IRR & $\begin{array}{c}\text { Payback } \\
\text { Period }\end{array}$ \\
\hline 1. & 0 & 0 & 0 & 601.522 .887 & 1,50 & $47,55 \%$ & 1,8 tahun \\
\hline 2. & $5 \%$ & 0 & 0 & (183.720.130) & 0,85 & $8,21 \%$ & $(0,5)$ tahun \\
\hline 3. & 0 & $5 \%$ & 0 & $(183.720 .130)$ & 0,85 & $8,21 \%$ & $(0,5)$ tahun \\
\hline 4. & 0 & 0 & $5 \%$ & $(80.398 .680)$ & 0,93 & $13,78 \%$ & $(2,9)$ tahun \\
\hline 5. & $5 \%$ & $5 \%$ & 0 & (929.700.996) & 0,23 & $(24,21) \%$ & 0,9 tahun \\
\hline 6. & $5 \%$ & 0 & $5 \%$ & (865.641.697) & 0,28 & $(26,72) \%$ & 0,9 tahun \\
\hline 7. & 0 & $5 \%$ & $5 \%$ & $(865.641 .697)$ & 0,28 & $(26,72) \%$ & 0,9 tahun \\
\hline 8. & $5 \%$ & $5 \%$ & $5 \%$ & (1.611.622.564) & $(0,34)$ & $(34,67) \%$ & 1,1 tahun \\
\hline
\end{tabular}

Sumber: Data primer 2017 (diolah)

Berdasarkan ringkasan hasil analisis sensitivitas pada Tabel 6 diatas, dapat dilihat bahwa yang paling sensitif terhadap perubahan dari nomor 5-7 yaitu pada nomor 5 terjadi penurunan harga jual dan penurunan volume produksi secara bersamaan, dengan nilai NPV sebesar Rp. (929.700.996). Net B/C sebesar 0,23, IRR sebesar $(24,21) \%$, dan Payback Period 0,9 tahun. Harga jual dan volume produksi merupakan suatu penentuan terhadap besarnya pendapatan (penerimaan) yang didapat oleh perusahaan. Jika harga jual dan volume produksi mengalami penurunan, maka pendapatan perusahaan juga akan turun.

Analisis Kelayakan Finansial Industri Penyulingan Minyak Pala Studi Kasus di UD.Palatama 252 Raya Kecamatan Tapaktuan Kabupaten Aceh Selatan (Hesti Rahmasari, Rahmaddiansyah, Zakiah) Jurnal Ilmiah Mahasiswa Pertanian Unsyiah, Vol 3, No 2, Mei 2018: 242-255 


\section{SIMPULAN DAN SARAN}

\section{Simpulan}

Berdasarkan hasil dan pembahasan penelitian ini, dapat disimpulkan sebagai berikut:

1. Upaya UD. Palatama Raya untuk memenuhi bahan baku dalam memproduksi minyak pala yaitu menanam pala dilahan pribadi dan membeli pasokan bahan baku dari daerah luar Aceh Selatan.

2. Berdasarkan kriteria kelayakan investasi pada UD. Palatama Raya dinyatakan layak dengan nilai NPV yaitu Rp. 601.522.887, Net B/C yaitu 1,50, IRR yaitu 47,55 \% dan PP 1,8 tahun. Berdasarkan hasil analisis BEP, dapat diketahui bahwa UD. Palatama Raya akan mengalami titik impas pada saat volume produksi yaitu $2.830 \mathrm{Kg}$ dan mendapatkan omset sebesar Rp. 1.808.832.597 dalam setahun agar mencapai BEP. Berdasarkan hasil analisis ROI UD. Palatama Raya, kemampuan mengembalikan investasi produksi minyak pala pada tahun ke-1 yaitu sebesar 53,8 \%, pada tahun ke-2 yaitu sebesar 56,5\% dan pada tahun ke-3 yaitu sebesar $60,1 \%$.

3. Analisis sensitivitas terhadap kriteria kelayakan investasi, diketahui bahwa UD. Palatama Raya paling sensitif terhadap penurunan harga jual dan penurunan volume produksi terjadi secara bersamaan.

\section{Saran}

Berdasarkan hasil dan pembahasan penelitian ini, dapat diberikan saran sebagai berikut:

1. Sebaiknya kondisi persediaan bahan baku ditingkatkan lagi supaya tidak terjadi keterbatasan bahan baku yang akan berdampak kepada proses produksi dan keuntungan perusahaan yang tidak stabil. Salah satu caranya yaitu intensifikasi lahan pala.

2. Sebaiknya kondisi volume produksi perusahaan ditingkatkan lagi supaya tidak terjadi penurunan volume produksi yang akan berdampak kepada keuntungan perusahaan yang tidak stabil. Dengan cara membeli pasokan bahan baku sampai keluar kota dan mengadopsi alat penyulingan yang lebih modern.

3. Sebaiknya kondisi harga jual perusahaan ditingkatkan lagi supaya tidak terjadi penurunan harga jual yang akan berdampak kepada keuntungan perusahaan yang tidak stabil. Salah satu caranya yaitu bekerjasama dengan pedagang-pedagang besar untuk menentukan harga jual.

\section{DAFTAR PUSTAKA}

Adiwijaya, Jemi; Uyun Erma Malika. 2013. Kelayakan Usaha Penyulingan Minyak Atisiri Berdasarkan Aspek Finansial dan Teknologi. Institut Pertanian Bogor, Bogor. Jurnal Ilmiah Inovasi. Vol 1, No 3 : 136.

Badan Pusat Statistik. 2002. Statistik Industri Besar dan Sedang. BPS, Jakarta.

Diasz, Alice; Wardis Girsang, Maisie T. F. Tuhumary. 2013. Studi Kelayakan

Usaha Penyulingan Minyak Pala (Myristica Fragrant Houtt) dan Strategi Pengembangannya (Studi Kasus Pada UD. Bintang Timur di Desa Hukurikula Kecamatan Leitimur Selatan Kota Ambon). Universitas Pattimura, Ambon. Jurnal Agribisnis Kepulauan. Vol 1, No 4 : 71.

Analisis Kelayakan Finansial Industri Penyulingan Minyak Pala Studi Kasus di UD.Palatama 253 Raya Kecamatan Tapaktuan Kabupaten Aceh Selatan (Hesti Rahmasari, Rahmaddiansyah, Zakiah) Jurnal Ilmiah Mahasiswa Pertanian Unsyiah, Vol 3, No 2, Mei 2018: 242-255 
Djamin, Z. 1992. Perencanaan dan Analisa Proyek. Fakultas Ekonomi Universitas Indonesia, Jakarta.

Gittinger, J. Price. 1986. Analisa Ekonomi Proyek-Proyek. Pertanian. Penerjemah Slamet. Universitas Indonesia, Jakarta.

Guenther, E. 1987. Minyak Atsiri. Jilid I. Universitas Indonesia Press, Jakarta

Harris, R. 1987. Tanaman Minyak Atsiri. Penebar Swadaya, Jakarta

Hasibuan, Malayu. 1994. Manajemen Sumberdaya Manusia. Haji Masagung, Jakarta.

Hatta, S.1993. Budidaya Pala Komoditas Ekspor. Yogyakarta

Kadariah, Karlina L, Gray C. 1976. Pengantar Evaluasi Proyek. Edisi Revisi. Universitas Indonesia Press, Jakarta.

Lutony, T.L. Yeyet Rahmayati. 2002. Produksi dan Perdagangan Minyak Atsiri. Penebar Swadaya, Jakarta.

Laksono, Mujito Sandi. 2015. Analisa Kelayakan Ekonomi dan Strategi Pengembangan Usaha Konveksi Cahaya Permata. Universitas Pancasakti Tegal. Jurnal Fakultas Teknik Industri. Vol 11, No 2 : 18.

Lusianah. 2009. Strategi dan Prospek Pengembangan Industri Produk Olahan Minyak Pala dalam Rangka Pemberdayaan Masyarakat di Kabupaten Bogor. Institut Pertanian Bogor, Bogor. Jurnal Manajemen Pengembangan Industri Kecil Menengah. Vol 5, No $1: 78-79$.

Muhajjir Afif dan Wahyu Ribut Setiawan. 2014. Analisis Penetapan Break Even Point Pada Produk Spirulina di PT. Neoalgae Indonesia Makmur Gresik. Universitas Gresik, Gresik. Jurnal Fakultas Ekonomi. Vol 3, No 2 : 56.

Naiborhu, Anugrah P. 2004. Analisis Kelayakan Finansial dan Pemasaran Minyak Pala (Myristica Fragrant Houtt) Studi Kasus pada PT. Pavettia Atsiri Indonesia di Bogor. Skripsi. Institut Pertanian Bogor, Bogor.

Nurdjannah, N. 2007. Teknologi Pengolahan Pala. Badan Penelitian dan Pengembangan Pertanian. Balai Besar Penelitian dan Pengembangan Pascapanen Pertanian. IPB, Bogor.

Oktavianingsih, Erna. 2010. Analisis Break Even Point (BEP) Komoditas Minyak Pala di PT. Perkebunan Nusantara IX (Persero) Kebun Ngobo Semarang Tahun 2004-2008. Skripsi. Universitas Sebelas Maret, Semarang.

Partadirja, Ace. 1985. Pengantar Ekonomi. BPFE, Yogyakarta

Rahmat, R. 2004. Usaha Tani Pala. Aneka Ilmu, Semarang.

Rahardja, Pratama. Mandala Manurung. 2002. Teknologi Ekonomi Mikro Suatu Pengantar. Fakultas Ekonomi Universitas Indonesia, Jakarta.

Rangkuti, Freddy. 2004. The Power Of Brand. PT. Gramedia Pustaka Utama, Jakarta.

Rismunandar, 1990. Budidaya dan Tata Niaga Pala. Cetakan kedua. PT. Penebar Swadaya, Jakarta.

Rismunandar, 1992. Budidaya dan Tata Niaga Pala. Penebar Swadaya, Jakarta.

Sastrohamidjojo, H. 2004. Kimia Minyak Atsiri. Gadjah Mada University Press, Yogyakarta

Siswanto B, Sastrohadiwiryo. 2002. Manajemen Tenaga Kerja Indonesia. Edisi 2. PT. Bumi Aksara, Jakarta.

Sukirno, Sadono. 2002. Teori Mikro Ekonomi. Cetakan Keempat Belas. Rajawali Press, Jakarta.

Sunanto, Hatta. 1993. Budidaya Pala Komoditas Ekspor. Kanisius, Yogyakarta.

Analisis Kelayakan Finansial Industri Penyulingan Minyak Pala Studi Kasus di UD.Palatama 254 Raya Kecamatan Tapaktuan Kabupaten Aceh Selatan (Hesti Rahmasari, Rahmaddiansyah, Zakiah) Jurnal Ilmiah Mahasiswa Pertanian Unsyiah, Vol 3, No 2, Mei 2018: 242-255 
Sumaatmaja, N. 1981. Suatu Pendekatan Dan Analisis Keruangan, Bandung.

Sutrisno. 2001. Manajemen Keuangan Teori, Konsep dan Aplikasi. Edisi Pertama. Penerbit Ekonisia, Yogyakarta.

Suwarsono, H. Muhammad, S. 2000. Studi Kelayakan Proyek. UUP STIM YKPN, Yogyakarta

Soeheroe, T. 1994. Matematika Ekonomi. Fakultas Ekonomi Universitas Indonesia, Jakarta.

Soekartawi. 2005. Agribisnis (Teori dan Aplikasinya). PT Raja Grafindo Persada, Jakarta.

Syarif, K. 2011. Analisis Kelayakan Usaha Produk Minyak Aromatik Merk Flosh. Fakultas Ekonomi dan Manajemen. Institut Pertanian Bogor, Bogor.

Umar, Husein. 2005. Study Kelayakan Bisnis . Edisi 3 Revisi. Gramedia Pustaka Utama, Jakarta. 